Check for updates

Cite this: RSC Adv., 2017, 7, 27895

Received 11th April 2017

Accepted 22nd May 2017

DOI: $10.1039 / c 7 r a 04114 d$

rsc.li/rsc-advances

\section{The influence of fractal nature on schwertmannite adsorption properties}

\author{
Chunyong Zhang, (D) *ab Zhefeng Zhang, ${ }^{a}$ Mengna Chen ${ }^{a}$ and Degang Fu ${ }^{\mathrm{b}}$
}

\begin{abstract}
Schwertmannite (SCH), a ferric oxyhydroxy sulfate mineral, had attracted extensive interests due to its excellent adsorption performance in decontamination processes. The present study initially explored the fractal properties of SCH by SEM imaging and nitrogen adsorption analysis. The two SCH samples under investigation were synthesized through chemical and biological routes, respectively. Our results revealed that biosynthesized $\mathrm{SCH}$ exhibited higher inner fractal dimension but lower surface fractal dimension than chemosynthesized $\mathrm{SCH}$. These outcomes were in line with their differing adsorption capabilities toward humic acid and $\mathrm{Cr}(\mathrm{VI})$. As a result, the employment of fractal geometry had led to new dimension of understanding the structure-property relationship in $\mathrm{SCH}$.
\end{abstract}

\section{Introduction}

Schwertmannite (SCH), an amorphous Fe-oxyhydroxy sulfate mineral $\left(\mathrm{Fe}_{8} \mathrm{O}_{8}(\mathrm{OH})_{x}\left(\mathrm{SO}_{4}\right)_{y}, x=8-2 \mathrm{y}, 1<y<1.75\right)$, has gained increasing attention in recent years for its excellent and unique adsorption properties. ${ }^{1-3}$ It has been shown that the structural, morphological and adsorptive properties of $\mathrm{SCH}$ are strongly dependent on the synthesis processes. ${ }^{3}$ Presently, SCHs are mainly synthesized through biological and chemical routes (i.e. bio-SCH and chemo-SCH). ${ }^{4}$ Previous studies have demonstrated that bio-SCH and chemo-SCH exhibit quite different surface morphology and adsorption ability. ${ }^{5,6}$ Such differences are usually explained in terms of microstructure and BET surface area. ${ }^{7}$ Note that one of the major issues involved is to experimentally extract the microstructure from SCH. Unfortunately, it remains a challenging task due to the lack of effective methods and techniques. In this scenario, a novel mathematical tool named fractal geometry was adopted in the present study. It was well proven that this tool was capable of describing the irregular and complex geometries of various solid materials. ${ }^{8}$ Specifically, a scale-dependent parameter named fractal dimension $\left(D_{\mathrm{f}}\right)$ was proposed to quantify the degree of structure irregularity. ${ }^{9}$ It is known that the understanding of adsorption process requires a detailed knowledge of surface morphology and pore structure. ${ }^{1}$ Thus, the employment of fractal geometry in such studies is quite appropriate. The $D_{\mathrm{f}}$ of SCH may give valuable information on the structures and irregularities of surfaces and pores, as well as on the major influencing

${ }^{a}$ Department of Chemistry, College of Science, Nanjing Agricultural University, Nanjing 210095, China

${ }^{b}$ State Key Laboratory of Bioelectronics, Southeast University, Nanjing 210096, China. E-mail: zhangchy@njau.edu.cn; Fax: +86 25 84395207; Tel: +86 2584395207

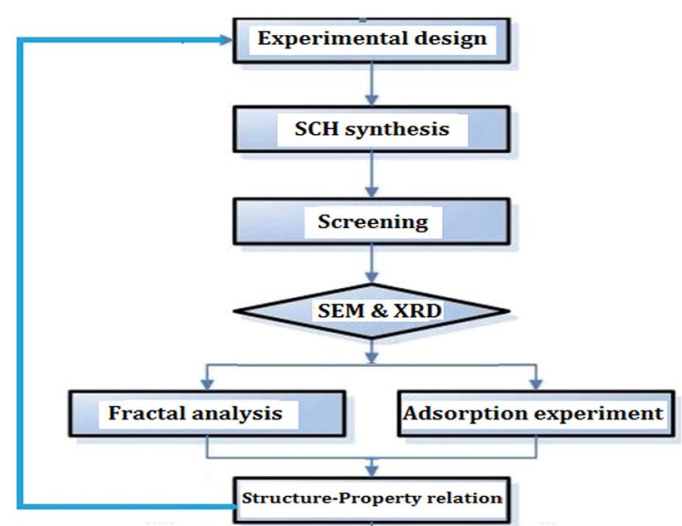

Fig. 1 The graphical representation of the present experimental works.

factors that are mainly responsible for the adsorption performance. However, to our knowledge, microstructure characterization of SCH via fractal geometry has not been reported yet.

Thus, the mission of this article was to investigate the fractal properties of both bio-SCH and chemo-SCH. We applied SEM imaging and nitrogen adsorption analysis to determine $D_{\mathrm{f}}$ values which are directly linked to the adsorption properties of SCH..$^{\mathbf{1 0 , 1 1}}$ We also investigated the influence of pollutant nature on the adsorption performance in order to gain deeper insights into the surface and pore structures of this mineral. Fig. 1 displays the graphic representation of the experimental works conducted. As expected, achieved results deepened our understanding on the relationship between microstructure and adsorption property in SCH. 


\section{Experimental}

\subsection{Reagents and materials}

All the chemicals were of the reagent grade and used as received. Solutions containing humic acid (HA, in the form of sodium salt) and $\mathrm{Cr}(\mathrm{vI})$ (in the form of $\mathrm{K}_{2} \mathrm{Cr}_{2} \mathrm{O}_{7}$ ) were freshly prepared by diluting the stock solution with deionized water. The A. ferrooxidans LX5 cell suspension was supplied by a biochemical laboratory of our university.

\subsection{Sample preparation}

Schwertmannite powders were prepared using two modified methods described in previous reports, ${ }^{12,13}$ in order to obtain different microstructures and adsorption properties.

Biosynthesis of SCH. The as-prepared $A$. ferrooxidans LX5 cell suspension was mixed with $120 \mathrm{~mL} 0.32 \mathrm{M} \mathrm{FeSO}_{4}$ aqueous solutions ( $\mathrm{pH} 2.5$ ) in an Erlenmeyer flask. The flask was then incubated in a reciprocal shaker at $210 \mathrm{rpm}$ for 6 days, and the precipitates were separated with a Whatman no. 4 filter film. The final products were dried at $60{ }^{\circ} \mathrm{C}$ for $12 \mathrm{~h}$ after washing with $0.1 \mathrm{M} \mathrm{H}_{2} \mathrm{SO}_{4}$ and deionized water, respectively.

Chemosynthesis of SCH. $80 \mathrm{mM} \mathrm{FeCl}_{3}$ and $20 \mathrm{mM} \mathrm{Na}_{2} \mathrm{SO}_{4}$ were introduced into a beaker containing $2 \mathrm{~L}$ preheated $\left(60{ }^{\circ} \mathrm{C}\right)$ distilled water. The collected precipitates were then heated at $70{ }^{\circ} \mathrm{C}$ for $10 \mathrm{~min}$, and the cooled samples were placed in cellulose membranes and were dialysed against ultra-pure water for 30 days. The final products were freeze-dried to obtain a dry powder.

As expected, the two as-prepared $\mathrm{SCH}$ samples exhibited quite different colors (see Fig. 2). For comparison purposes, both samples were passed through 300 mesh screen before used in adsorption experiments. The corresponding XRD patterns of $\mathrm{SCH}$ (not shown here) demonstrated the same mineralogy as described in previous works, ${ }^{\mathbf{1 2 - 1 7}}$ suggesting that both samples were pure $\mathrm{SCH}$ with weak crystalline structures (please refer to these works for the detailed results).

\subsection{Analytical apparatus and calculations}

The surface $D_{\mathrm{f}}$ values were determined from the denoised SEM images at different imaging scales. Firstly, the original SEM images were obtained with Quanta 400 FEG scanning electron
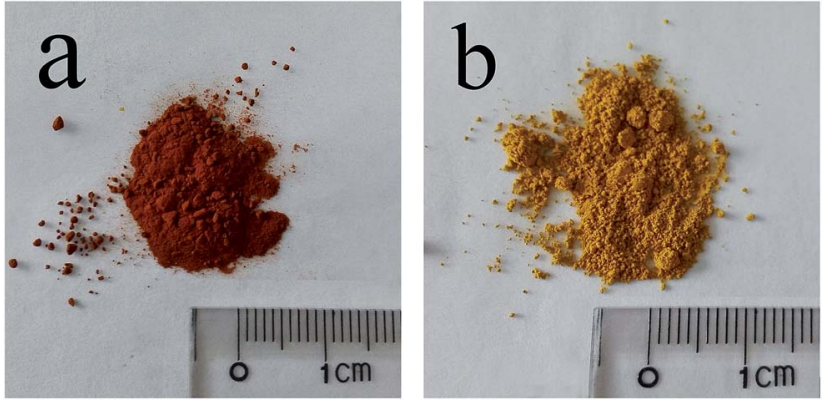

Fig. 2 Digital images of the as-prepared bio- $\mathrm{SCH}(\mathrm{a})$ and chemo-SCH (b). microscope (FEI, USA). Thereafter, these SEM images were subjected to Laplacian filters to remove the noises (the denoising regularization parameter was set as 1.0). ${ }^{10}$ Finally, the Triangular Prism Surface Area methodology of Fractal Fox 2.0 program was used to calculate the surface $D_{\mathrm{f}}$ values.

The inner $D_{\mathrm{f}}$ values were calculated by low-pressure nitrogen adsorption analysis, which was done on a V-Sorb 2800S SI Surface Area Analyzer (Gold APP, Beijing, China). According to the fractal FHH (Frenkel-Halsey-Hill) equation (eqn (1)), the inner $D_{\mathrm{f}}$ values were assessed by eqn (2): ${ }^{18}$

$$
\begin{gathered}
\ln (V)=k \ln \left(\ln \left(P_{0} / P\right)\right)+C \\
D_{\mathrm{f}}=3+k
\end{gathered}
$$

where $V$ was the adsorbed nitrogen volume at equilibrium pressure $\left(\mathrm{mL} \mathrm{g}^{-1}\right)$; $k$ was power-law exponent; $P_{0}$ and $P$ were the nitrogen pressures measured at saturation and equilibrium conditions, respectively (MPa); and $C$ was an adsorption constant.

\subsection{Adsorption experiments}

The adsorptive capability of $\mathrm{SCH}$ as a function of contact time was investigated in batch mode. $100 \mathrm{mg} \mathrm{SCH}$ sample was introduced into a stoppered conical flask containing $100 \mathrm{~mL}$ aqueous solution (containing $40 \mathrm{mg} \mathrm{L}^{-1} \mathrm{HA}$ or $40 \mathrm{mg} \mathrm{L}^{-1} \mathrm{Cr}(\mathrm{vI})$ ). At preset time intervals, the residual $\mathrm{HA}$ and $\mathrm{Cr}(\mathrm{vI})$ concentrations were determined with Shimadzu UV-1800 spectrophotometer and Hitachi Z-2000 atomic absorption spectrometer, respectively. The adsorptive capacity $\left(Q, \mathrm{mg} \mathrm{g}^{-1}\right)$ was calculated by eqn (3):

$$
Q=\left(c_{0}-c\right) V / w
$$

where $c_{0}$ and $c$ were the initial and final concentrations of pollutant, respectively $\left(\mathrm{mg} \mathrm{L}^{-1}\right)$; $V$ was the solution volume (L); and $w$ was the weight of SCH sample (g).

\section{Results and discussions}

It is known that self-similarity and fractal dimension are two most important properties of fractal objects, but most fractals are invariant only under certain length scales. ${ }^{19}$ In other words, the morphology of real materials can only be mapped into finite fractal. With this in mind, we illustrate the SEM images of the two tested SCHs (bio-SCH and chemo-SCH) at different imaging scales (0.5-50 $\mu \mathrm{m})$ (Fig. 3).

The main observations from these micrographs are: (1) both SCHs exhibit rough surfaces, indicating large surface area and excellent adsorption capability; (2) the surfaces of bio-SCH give the appearances of sea urchin and flower at low and high imaging scales, respectively; (3) another intriguing feature of bio-SCH is the macropore among the network, which indicates extra adsorption sites inside the powders; and (4) the surfaces of chemo-SCH are amorphous at all imaging scales adopted. 

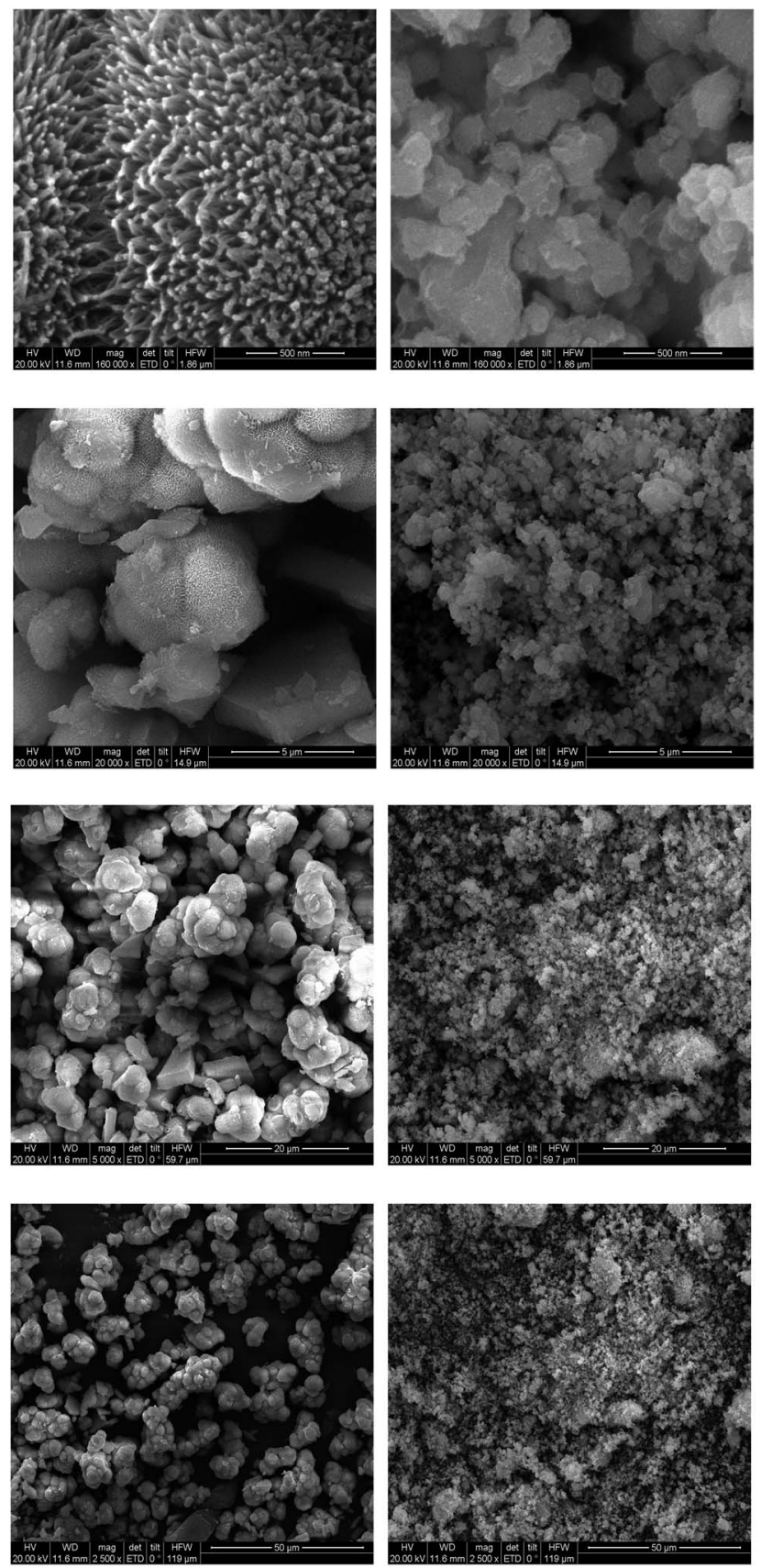

Fig. 3 SEM images of bio-SCH (the 1st column) and chemo-SCH (the 2nd column) at different imaging scales.

The surface $D_{\mathrm{f}}$ values were then calculated from the denoised SEM images and the results were presented in Table 1. Some phenomena may thus be observed:

(1) All the surface $D_{\mathrm{f}}$ values obtained are quite high (2.4-2.7), thus offering an essential explanation for the excellent performance of $\mathrm{SCH}$ in adsorption processes;

(2) The microstructures of both SCHs can be described as being self-similar within a cutoff length scale (i.e. 5-50 $\mu \mathrm{m})$. At lower scales (i.e. $0.5 \mu \mathrm{m}$ ), the surface $D_{\mathrm{f}}$ values are scale dependent, confirming the finite fractal nature of $\mathrm{SCH}$;
Table 1 The surface fractal dimensions of $\mathrm{SCH}$ samples versus different scales of SEM images

\begin{tabular}{llllll}
\hline Scales & $0.5 \mu \mathrm{m}$ & $5 \mu \mathrm{m}$ & $20 \mu \mathrm{m}$ & $50 \mu \mathrm{m}$ & Mean value \\
\hline Bio-SCH & 2.572 & 2.484 & 2.501 & 2.498 & 2.514 \\
Chemo-SCH & 2.473 & 2.565 & 2.596 & 2.619 & 2.563 \\
\hline
\end{tabular}

(3) The mean surface $D_{\mathrm{f}}$ value of chemo-SCH (2.563) is higher than that of bi-SCH (2.514), indicating that chemo-SCH may demonstrate better adsorption performance than bio-SCH in certain cases (e.g., when the adsorption mainly occurs on the surface of $\mathrm{SCH}$ ).

The foregoing results concerning the inner structures of $\mathrm{SCH}$ were obtained with low-pressure nitrogen adsorption analysis. Table 2 presents the main adsorption properties from such analysis. Clearly bio-SCH is superior to chemo-SCH in terms of both surface area and adsorption volume. However, adsorption by $\mathrm{SCH}$ in aqueous solution is also influenced by the physicochemical properties of pollutant, such as water solubility, molecular weight and size, surface charge and function group, polarity, and etc. ${ }^{2,3}$ As a consequence, the adsorptive capacity of bio-SCH may be higher or lower than that of chemo-SCH, depending on the nature of pollutant molecules adopted (which will be confirmed by the following experiments).

The nitrogen adsorption-desorption isotherms of the $\mathrm{SCH}$ samples are shown in Fig. 4. As can be seen, compared to those of bio-SCH, the total $\mathrm{N}_{2}$-adsorbed volume of chemo-SCH is lower, and the desorption hysteresis loop is narrower. These outcomes evidence that bio-SCH enables higher adsorption volume than chemo-SCH, and desorption of nitrogen gas at bio$\mathrm{SCH}$ is more difficult than that at chemo-SCH. ${ }^{20}$

According to FHH equation, the plots of $\ln (V) v s . \ln \left(\ln \left(P_{0} / P\right)\right)$ of the two SCH samples are presented in Fig. 5 (both with excellent linearity, $R^{2}>0.99$ ). The calculated inner $D_{\mathrm{f}}$ values are 2.699 and 2.592 for bio-SCH and chemo-SCH, respectively. This means the pore structure of bio-SCH is more complicated. Hence, the diffusion and desorption of pollutant molecule in bio-SCH are more difficult than those in chemo-SCH. The result is also in well accordance with that recorded in SEM images (see Fig. 3). It has been proven that the macropores in porous materials serve as conduits for transporting the pollutant molecule from the outer particle surfaces to the interior surfaces (where part of the adsorption occurs), but big molecules cannot pass through these macropores. ${ }^{21}$

As mentioned above, the size and molecular weight of pollutant model may play vital roles in determining the adsorption performance of SCH. To confirm the hypothesis, two different pollutants (HA and $\mathrm{Cr}(\mathrm{VI})$ ) were employed in the following comparative experiments. Operating conditions being equal, the influences of reaction time on the adsorptive capacity $(Q)$ of both SCHs are depicted in Fig. 6.

Clearly for most cases, adsorption processes are rapid as the adsorption capacities attain equilibrium after $1 \mathrm{~h}$. For HA, the mean $Q$ values are $12.3 \mathrm{mg} \mathrm{g}^{-1}$ and $15.1 \mathrm{mg} \mathrm{g}^{-1}$ for bio-SCH and chemo-SCH, respectively. While for $\mathrm{Cr}(\mathrm{vI})$, the corresponding $Q$ 
Table 2 The adsorption properties of bio- $\mathrm{SCH}$ and chemo-SCH

\begin{tabular}{|c|c|c|c|c|}
\hline $\begin{array}{l}\text { Adsorption } \\
\text { properties }\end{array}$ & $\begin{array}{l}\text { BET surface } \\
\text { area }\left(\mathrm{m}^{2} \mathrm{~g}^{-1}\right)\end{array}$ & $\begin{array}{l}\text { Langmuir surface } \\
\text { area }\left(\mathrm{m}^{2} \mathrm{~g}^{-1}\right)\end{array}$ & $\begin{array}{l}\text { BJH adsorption } \\
\text { cumulative volume }\left(\mathrm{cm}^{3} \mathrm{~g}^{-1}\right)\end{array}$ & $\begin{array}{l}\text { Single point adsorption } \\
\text { total pore volume }\left(\mathrm{cm}^{3} \mathrm{~g}^{-1}\right)\end{array}$ \\
\hline Bio-SCH & 34.55 & 58.13 & 7.938 & 0.086 \\
\hline
\end{tabular}

values are $5.5 \mathrm{mg} \mathrm{g}^{-1}$ and $4.2 \mathrm{mg} \mathrm{g}^{-1}$, respectively. These outcomes are reasonable since in case of big molecules (HA), the outer particle surfaces (not the interior surfaces) of $\mathrm{SCH}$ powders are mainly responsible for their adsorption performance. As a result, these interesting findings strongly support the view that adsorptive capacities of porous materials also depend strongly on the nature of pollutant molecule.

Overall, the results from fractal analysis contribute to the understanding of the surface morphological characteristics and
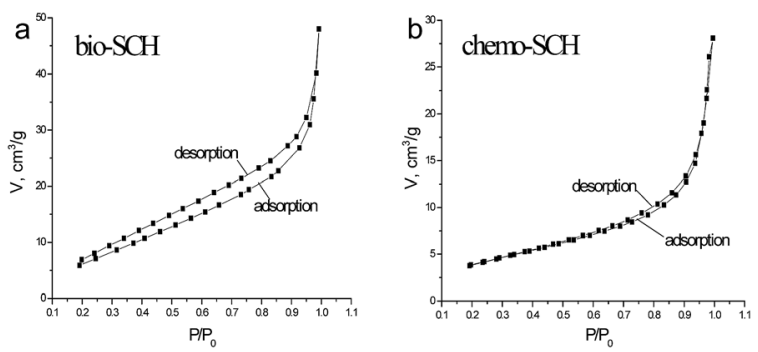

Fig. 4 The nitrogen adsorption-desorption isotherm of the $\mathrm{SCH}$ samples.
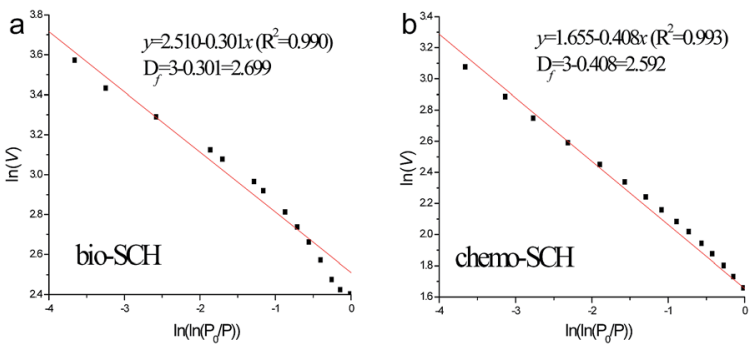

Fig. 5 Plots of $\ln (V)$ vs. $\ln \left(\ln \left(P_{0} / P\right)\right)$ reconstructed from the nitrogen adsorption data.
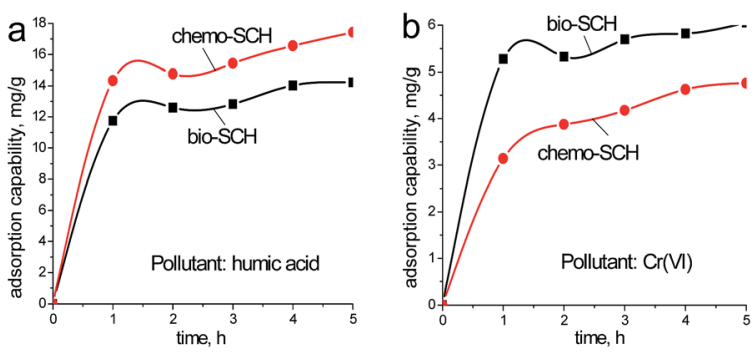

Fig. 6 Adsorption kinetics of humic acid and $\mathrm{Cr}(\mathrm{VI})$ onto bio- $\mathrm{SCH}$ and chemo-SCH (initial humic acid and $\mathrm{Cr}(\mathrm{VI})$ concentration: $40 \mathrm{mg} \mathrm{L}^{-1}$, adsorbent dosage: $100 \mathrm{mg}$ and at $25^{\circ} \mathrm{C}$ ). pore structures of SCH. The surface and inner $D_{\mathrm{f}}$ values of $\mathrm{SCH}$ can be considered as the operative measurements of surface roughness and pore complexity, respectively. Despite this, the microstructures of $\mathrm{SCH}$ are still far from entirely understood. The underlying reason is, besides $D_{\mathrm{f}}$ values and pollutant size, the other factors mentioned previously must also be properly handled before a truly comprehensive understanding can be realized..$^{22,23}$ Future works are being planned to establish a quantitative correlation between fractal dimension and adsorptive capacity by investigating the interactive effects between $\mathrm{SCH}$ and pollutant molecule.

\section{Conclusions}

In this work, we presented a fractal study on the surface morphology and inner structure of SCHs. It had been demonstrated that the surfaces of both bio-SCH and chemo-SCH possessed typical fractal characteristics. Moreover, the surface and inner fractal dimensions of SCHs were proven to be dependent on the type of precursors and synthesis methods. Meanwhile, a comparison on the adsorptive capacities of SCHs also revealed the important role of pollutant nature. These results gave novel structural aspects of the adsorption properties of $\mathrm{SCH}$, which were useful for further exploration of new SCH-based adsorbents.

\section{Acknowledgements}

This study has received funding from the Fundamental Research Funds for the Central Universities (KYZ201648). We wish to express our sincere thanks for the two reviewers for their helpful comments and suggestions.

\section{References}

1 S. H. Aloune, T. Kawaai, N. Hiroyoshi and M. Ito, Hydrometallurgy, 2014, 147-148, 30-40.

2 E. D. Burton, S. G. Johnson, K. M. Watling, R. T. Bush, A. F. Keene and L. A. Sullivan, Environ. Sci. Technol., 2010, 44, 2016-2021.

3 A. Eskandarpour, M. S. Onyango, A. Ochieng and S. Asai, J. Hazard. Mater., 2008, 152, 571-579.

4 P. Susanta and P. Stefan, Water, Air, Soil Pollut., 2012, 223, 2933-2942.

5 M. Gan, S. Sun, Z. Zheng, H. Tang, J. Sheng, J. Zhu and X. Liu, Appl. Surf. Sci., 2015, 356, 986-987.

6 M. A. Caraballo, J. D. Rimstidt, F. Macías, J. M. Nieto and M. F. Hochella, Chem. Geol., 2013, 360-361, 22-31. 
7 J. Guo, C. Dong, J. Zhang and Y. Lan, Sep. Purif. Technol., 2015, 143, 27-31.

8 Q. Wang, Z. Liang, X. Wang, W. Zhao, Y. Wu and T. Zhou, Appl. Surf. Sci., 2015, 327, 182-189.

9 Q. Zeng, M. Luo, X. Pang, L. Li and K. Li, Appl. Surf. Sci., 2013, 282, 302-307.

10 S. Dhillon and R. Kant, Appl. Surf. Sci., 2013, 282, 105-114.

11 L. Sandoval-Díaz, J. Aragon-Quiroz, Y. Ruíz-Cardona, A. Domínguez-Monterroza and C. Trujillo, Microporous Mesoporous Mater., 2017, 237, 260-267.

12 P. Zhou, Y. Li, Y. Shen, Y. Lan and L. Zhou, J. Hazard. Mater., 2012, 237-238, 194-198.

13 J. M. Bigham, U. Schwertmann, S. J. Traina, R. L. Winland and M. Wolf, Geochim. Cosmochim. Acta, 1996, 60, 21112121.

14 S. HoungAloune, N. Hiroyoshi and M. Ito, Min. Eng., 2015, 74, 51-59.
15 Y. Liao, J. Liang and L. Zhou, Chemosphere, 2011, 83, 295301.

16 Y. Liao, L. Zhou, J. Liang and H. Xing, Mater. Sci. Eng., Proc. Conf., 2009, 29, 211-215.

17 Y. Wu, J. Guo, D. Jiang, P. Zhou, Y. Lan and L. Zhou, Environ. Sci. Pollut. Res., 2012, 19, 2313-2320.

18 X. Liu, J. Xiong and L. Liang, J. Nat. Gas Sci. Eng., 2015, 22, 62-72.

19 S. Kulesza and M. Bramowicz, Appl. Surf. Sci., 2014, 293, 196201.

20 C. Zhang, H. Cui, Z. He, L. Su and D. Fu, $R S C A d v .$, 2016, 6, 8639-8643.

21 R. Smajda, A. Kukovecz, Z. Konya and I. Kiricsi, Carbon, 2007, 45, 1176-1184.

22 S. Lata and S. R. Samadder, J. Environ. Manage., 2016, 166, 387-406.

23 E. Kumar, A. Bhatnagar, W. Hogland, M. Marques and M. Sillanpaa, Chem. Eng. J., 2014, 241, 443-456. 